\title{
Communication Skills to Develop Trusting Relationships on Global Virtual Engineering Capstone Teams
}

\author{
Holt Zaugg \\ Brigham Young University - Provo, holt_zaugg@byu.edu \\ Randall Davies \\ Brigham Young University - Provo
}

Follow this and additional works at: https://scholarsarchive.byu.edu/facpub

Part of the Library and Information Science Commons

\section{Original Publication Citation}

Zaugg, Holt; Davies, Randall S,. Communication Skills to Develop Trusting Relationships on Global Virtual Engineering Capstone Teams. European Journal of Engineering Education, v38 n2 p228-233 2013

\section{BYU ScholarsArchive Citation}

Zaugg, Holt and Davies, Randall, "Communication Skills to Develop Trusting Relationships on Global Virtual Engineering Capstone Teams" (2013). Faculty Publications. 1634.

https://scholarsarchive. byu.edu/facpub/1634

This Peer-Reviewed Article is brought to you for free and open access by BYU ScholarsArchive. It has been accepted for inclusion in Faculty Publications by an authorized administrator of BYU ScholarsArchive. For more information, please contact ellen_amatangelo@byu.edu. 


\title{
Communication Skills to Develop Trusting Relationships on Global Virtual Engineering Capstone Teams
}

\author{
Holt Zaugg \\ zauggh@gmail.com
}

Randy Davies

\begin{abstract}
As universities seek to provide cost effective, cross-cultural experiences using global virtual $(\mathrm{GV})$ teams, the "soft" communication skills typical on all teams, increases in importance for $\mathrm{GV}$ teams. Students need to be taught how to navigate through cultural issues and virtual tool issues to build strong trusting relationships with distant team members. Weekly team meetings provide an excellent opportunity to observe key team interactions that facilitate relationship and trust building among team members.

This study observed the weekly team meetings of engineering students attending two U.S. universities and one Asian university as they collaborated as a single GV capstone GV team. In addition local team members were interviewed individually and collectively throughout the project to determine strategies that facilitated team relations and trust. Findings indicate the importance of student choice of virtual communication tools, the refining of communication practices, and specific actions to build trusting relationships. As student developed these attributes, collaboration and success was experienced on this GV team.
\end{abstract}

Keywords: global virtual teams, cross-cultural interactions, communication skills, trusting relationships 


\section{A. Introduction}

In an effort to provide more cost effective, cross-cultural experiences for students, universities are turning to global virtual (GV) teams (Boule, 2008; Goold, Augar \& Farmer, 2006; Gavidia, Mogollon \& Baena, 2004). A GV team exists when team members, spread throughout the world, work together to solve a unique, real-world problem. Interaction among team members is facilitated by a variety of Internet-based technologies, that provide for synchronous and asynchronous communication to assist the sharing of information, documents, and tasks.

As more universities use global virtual (GV) teams with students from international partner universities, a greater reliance is placed on students' virtual communication skills (Sarker, et al., 2011). These communication skills are typically used in one-on-one team member interactions or whole team meetings and, in many disciplines, are considered to be the "soft" skills as they are not connected to the technical skills required to complete the task. While the soft skills are present and needed on co-located teams, the nature of these skills changes when interacting with GV team members. With different cultural backgrounds and the limitations of Internet interactions, as found on GV teams, the importance of soft skills increases as team members establish relationships. For example, nonverbal communications are limited when compared to the typical face-to-face team meetings. Virtual communication tools filter or eliminate the subtle non-verbal cues that help team members build trusting relationships on co-located teams (King, 2007). Often these filtered cues are the ones co-located team members use to build stronger relationships of trust.

Understanding how the soft communication skills develop and unfold on GV teams becomes a critical element of successful GV teams. Weekly GV team meetings provide an 
opportunity to gain insights into how GV teams use and develop their communication skills. As team members conduct weekly meetings (i.e. report findings, explain progress, and make assignments) successful communication skill development promotes stronger relationships of trust on $\mathrm{GV}$ teams.

This study used weekly GV team meetings to better understand the activities and interactions that develop trusting relationships with other students. Using a GV engineering capstone team with team members located in Pennsylvania State University (PSU), National University of Singapore (NUS), and Brigham Young University (BYU), weekly meetings were observed and team member interactions recorded to better understand how team members developed and used their soft skills using virtual tools. Due to study constraints, the study only observed the interactions in weekly team meetings from the perspective of BYU university subteam members.

\section{B. Capstone Teams}

The team consisted of three sub-teams, each located in its respective university. Each subteam consisted of 4-6 team members and a local coach to help guide and instruct the students. Each capstone sub-team was unique as far as team member culture and gender make-up. For example the BYU team consisted of five men and one woman. All of the men were from the U.S.A. and the woman was from Nepal. Similar diversity existed in the other sub-teams with most team members from the local culture but one or two members from another culture. All students from all sub-teams were in their third or fourth year of engineering studies.

In each university the capstone project was a culminating activity designed to challenge students with a real-life engineering project. BYU and NUS participated in the capstone project over two semesters, while PSU students were only involved for the Fall semester. This capstone 
project focused on designing a collapsible bicycle for use in Singapore and, as a result, NUS was the lead sub-team.

Weekly meeting times were determined by student schedules but typically occurred at one of two times - on the same day with BYU and PSU meeting early in the morning and NUS late at night (7:00 AM, 9:00 AM and 10:00 PM respectively) or BYU and PSU meeting in the evening and NUS in the morning of the next day (5:00 PM, 7:00 PM, and 7:00 AM respectively). Contact between individual members of each sub-team did occur, but was not common. Each sub-team was funded by their respective university and complied with the course guidelines established by their respective university. There was no attempt to align course content, guidelines, or outcomes between the three universities.

\section{Data Collection}

The researcher attended all weekly meetings to observe and audio-record all team interactions. The BYU team members were interviewed individually at the mid-point of the course and twice as a group, once in the middle of the first semester and at the completion of the project. In addition BYU sub-team members responded to a midpoint and end point survey to triangulate responses. Observations and interviews examined how BYU team members altered their communication skills while using virtual tools to facilitate interactions with other subteams. All team participants were given the chance to respond to the findings and write-up to confirm the accuracy of reported data.

\section{Results}

Observations and interviews identified three components to developing soft skills that facilitated stronger team member interactions (1) the choice and use of virtual communication 
tools, (2) the refinement of communication skills, and (3) the scheduling of time to build of trusting relationships.

Choice of virtual communication tools. Program restraints required virtual communication tools that were no cost to use, but familiar to students. Following this criteria, choice of virtual communication tools followed the pattern of familiarity, functionality, and practicality. Students were willing to explore new technologies, but switched when superior technologies were found. For example, in the first semester students used a real time communication tool that would only allow for audio between the three end points. However, as the second semester began a newer, tool was discovered that allowed for both audio and video sharing from several endpoints. The team switched to the newer technology and remained with it even as communication was reduced to two endpoints for team meetings.

The switch to the newer tool provided more information as team members could see distant team members, allowing for more non-verbal communication, individual identification, and fewer dropped calls during the meeting. One student commented on the difference the newer technology may have made for development of team trust and relationships. He stated, "I think the video chatting was way more effective than just audio. I think if we had video all the first semester, it could have made a stronger relationship and a stronger bond." This supports prior research asserting that more media rich tools facilitate greater team interactions and promote stronger team relationships (Erasmus, Pretorius, \& Pretorius, 2010; Hinds \& Bailey, 2003; Shachaf \& Hara, 2007). The greater the media richness the more verbal and non-verbal information can be sent. This includes placing a face to the name and voice of a team member (Daim et al., 2011). 
The team used the same document sharing, cloud technology throughout the duration of the project. In this case the virtual document sharing technology met the desired criteria of accessibility and compatibility with team meeting interactions. Arranging for the common sharing of documentation prior to team meetings facilitated team interactions during the meetings. One student stated, "When we had documentation to show, it made a lot easier to communicate. If we had prepared slides or whatever, it made our ideas come across a lot better than had we just tried to explain it." The cloud technology met this need of the team.

During team meetings, each sub-team would refer to a specifically labeled document for each sub-team to download. This document then focused the discussion of the team. At times team members used audio, video (in the second semester), text, document sharing and screen sharing technologies to convey their message. Using a variety of technologies supports previous research suggesting that a repertoire of tools facilitates GV team communication (Zaugg, 2012). The repertoire of tools allows students to pick which tool to use and the amount of tools to use with each communication.

Virtual tools were chosen because of familiarity, functionality, and practicality. Team members in each sub-team began using familiar tools, but were willing to explore and switch as better technologies were found. The tools met the needs for communication and knowledge synchronously and asynchronously. That is, students could speak and share ideas with one another in real time or over time. Finally each tool was used in such a way that helped move the project forward.

Refining communication practices. All sub-team interactions were filtered both by technology and culture. As a result communication became paramount in team interactions. The BYU sub-team leader summarized the change in communications by stating, "It's very important 
when someone says something to repeat it back to them to ensure that you understand what they mean. Be cognizant of what phrases you use so that team members, not familiar with idiomatic or just slang, can be sure that they understand what you mean."

In team meetings, students often asked sub-team members to clarify or repeat information to improve understanding. Students also limited their use of vernacular phrases or explained phrases to prevent a misunderstanding. After making statements, presenting students would often pause to ask if any clarification was needed or listening students would speak up to ask for the information to be repeated or explained in another way. Texting was often used when dialects prevented a clear enunciation of a word or phrase. While conversations assumed this repetitive nature, it became a critical element in ensuring clear understanding. In spite of these steps, students were still tentative in their discussions as all students were more cautious in what they said and how they said it.

This mirrors information provided by Barczak, McDonough and Athanassiou (2006) where GV team members were encouraged to allow time for comments to be digested and for an appropriate response to be formed. They also advocate forwarding key documents prior to team meetings so team members may review them and take the time needed to understand these documents. While this latter practice was not followed on by this team, by the end of the project students acknowledged previewing each sub-team's documents prior to the meetings as a factor that would have facilitated greater understanding and expedited decision making.

Building trusting relationships. Establishing and building relationships of trust proved to be the most challenging task for the GV team. Only using audio and limiting interaction to weekly meetings greatly limited the ability of team members to get to know one another and form trust with other sub-team members. In fact, trust between BYU and PSU was built 
somewhat by accident. During team meetings the NUS sub-team often lost their signal and was disconnected from the team interactions. While waiting for NUS to re-establish their connection, BYU and PSU students would visit about topics not related to the project. These little chats helped form a stronger initial trust between BYU and PSU.

When PSU left the project at the end of the semester, BYU realized that the practice of just visiting with the PSU sub-team had helped form a stronger relationship. Since there was not as strong with the NUS sub-team, the BYU sub-team began to schedule time before or after team meetings to just visit with their NUS counterparts. This action, coupled with the addition of video to team meetings, facilitated the development of stronger relationships with NUS students. As relationships were strengthened, new ideas were shared among team members.

One BYU student felt that "a key point was knowing them individually. It was a lot more enjoyable and I trusted people more when I knew their personality.” Knowing the nature of team members helps facilitate an understanding of who they are and what they can and will do. It facilitated positive disagreements where students were willing to challenge or defend designs. It also helped for students to speak up during meetings instead of allowing one or two people to speak for the sub-group. Gaining this personal knowledge and trust facilitated such exchanges between BYU and PSU, but to a lesser extent with NUS. This reflects the social networks built up between the two US schools during their time waiting for NUS to reconnect.

However, the team task also influenced the collaboration between the sub-teams. For example, the first semester focused heavily on design with each sub-team assuming a specific role. In the second semester, team efforts shifted to building a prototype. Since NUS and BYU were not able to obtain common materials, the two sub-teams built somewhat different 
prototypes. Although team members commented on each other's work and progress, the team task in the second semester did not require the same degree of collaboration.

Another trust building effort focused acknowledging the contributions of each sub-team. For example in December, NUS posted pictures of their summary report on Facebook and tagged BYU and PSU team members' contribution to the project. This action helped other team members think of the three groups as a single team instead of three separate teams. It also built trust as NUS gave credit where due by acknowledging the efforts and support of the other subgroups. When BYU posted project pictures on their Facebook account, they took similar steps to identify and acknowledge the efforts of all team members. This unifying of team identity became an important step in strengthening the relationships on the team. Cho et al. (2007) describes building social networks as important to facilitate team unity and interaction.

While there were social networks formed between sub-team members, the BYU students felt these relationships would have been strengthened by stratifying each sub-team with one or two members from each sub-team connecting to work on a specific aspect of the prototype. This would have ensured that each sub-team had access to similar materials and that the two prototypes were similar in construction. It would have also provided for more interactions and stronger trust being built between team members. This would indicate that the structure of the team would need to be modified as the team task also changed. This modification may have provided further interactions to strengthen team cohesion and purpose.

\section{E. Conclusion}

As students collaborate on GV teams it is important that they adopt an open attitude towards the use of Internet based tools. Although familiarity, functionality and practicality will continue to influence student choice, but a willingness to explore and try new tools is critical to 
improving communication between GV team members. The communication can only be as good as the tool used. Having a repertoire of tools enables students to pick the type and amount of tools to use in any communication.

Even when the team has a good selection of communication tools and the team is using a language common to all team members, students need to increase the practice of restating and clarifying. The reduction or elimination of colloquial phrases becomes an important step in this process until there is a greater understanding of the common language. Using precise, clear language facilitates communications and avoids misunderstanding that can hamper team progress and damage trust. Taking the time to visit about non-project activities and interests facilitates a better understanding and trust between team members. A trusting relationship is formed because team members know and better understand how other team members function in team situations and communications.

As team members know one another's personality and preferences, the team is able to adapt and just its structures to better fit the requirements of the team project. Thus, developing the communication soft skills facilitates a better knowledge of other team members. This increased knowledge helps team members understand how team members wish to communicate and collaborate. This understanding facilitates team adaptations that promote stronger trust between team members and the successful completion of team projects.

\section{F. Acknowledgements}

The author gratefully acknowledges the support provided by US National Science Foundation grant EEC 0948997 that made this research possible. 


\section{References}

Boule, M. (2008). Best Practices for Working in a Virtual Team Environment. Context, 44(1), 28-31.

Cho, H., Gay, G., Davidson, B., \& Ingraffea, A. (2007). Social networks, communication styles, and learning performance in a CSCL community. Computers \& Education, 49(2), 309-329. doi:10.1016/j.compedu.2005.07.003.

Daim, T. U., Ha, A., Reutiman, S., Hughes, B., Pathak, U., Bynum, W., \& Bhatla, A. (2011). Exploring the communication breakdown in global virtual teams. International Journal of Project Management. Elsevier Ltd and IPMA. doi:10.1016/j.ijproman.2011.06.004.

Erasmus, E., Pretorius, J. H. C., \& Pretorius, L.. (2010). Using Virtual Team Project Communication as a Means of Predicting Virtual Team Effectiveness. IEEE Xplore Digital Library, 3(4), 1-9.

Gavidia, J. V., Mogollon, R. H., \& Baena, C. (2004). Using International Virtual Teams in the Business Classroom. Journal of Teaching in International Business, 16(2), 51-74.

Goold, A., Augar, N., \& Farmer, J. (2006). Learning in Virtual Teams : Exploring the Student Experience. Journal of Information Technology Education, 5, 477-490.

Hinds, P. J., \& Bailey, D. E. (2003). Out of sight, out of sync: Understanding conflict in distributed teams. Organization Science, 14(6), 615-632. doi:10.1287/orsc.14.6.615.24872

King, C. (2007). Building trust in global virtual teams: an innovative training model. Development, 21(3), 315-320.

Sarker, S. [Saonee], Ahuja, M., Sarker, S. [Suprateek], \& Kirkeby, S. (2011). The Role of Communication and Trust in Global Virtual Teams: A Social Network Perspective. Journal of Management Information Systems, 28(1), 273-309. doi:10.2753/MIS0742-1222280109

Shachaf, P., \& Hara, N. (2010). Behavioral complexity theory of media selection: A proposed theory for global virtual teams. Journal of Information Science, 33(1), 63-75. doi: $10.1177 / 0165551506068145$

Zaugg, H. (2012) Communication Patterns Among Engineering Global Virtual Teams, Doctoral Dissertation, Brigham Young University, Provo, Utah. 